\title{
Research on the Application of the Chinese Traditional Culture on Product Design
}

\author{
Zhang Yan \\ Xi’an International University, Xi’an Shaanxi, 710077
}

\author{
Keywords: Chinese Traditional Culture; Product Design; Application
}

\begin{abstract}
Chinese traditional culture, many designers design the products with Chinese characteristics by integrating the traditional elements with the modern products, many products that are full of Chinese cultural characteristics have come into being. During the real development, the Chinese traditional cultural elements have been extensively shown in the modern life and production. We could easily find out the colors, materials, and patterns are shown in the products such as tea sets, table wares, industrial products, articles for daily use, and electronic products, etc. These kinds of products could not only develop the Chinese traditional culture further more, but easily restore the Chinese style and Chinese characteristics. Therefore, this thesis discusses the application of the Chinese traditional culture on product design.
\end{abstract}

Chinese traditional culture is the quintessence that has developed for thousands of years; it is the unique cultural treasure of China. After five thousand years' constant development, reformation, and innovation, China has entered the $21^{\text {st }}$ century in which the technology is developing fast. In the developmental process, the Chinese people discard the waste matters and persist in the quintessence of their culture. But, at the sometime, many traditional products with strong medieval characteristics are gradually disappearing ${ }^{[1]}$. Therefore, to apply the Chinese traditional culture to the modern product design is a kind of cultural recurrence. It is a very important way to show the characteristics of China. This thesis discusses this issue as below.

\section{The relativity between the Chinese traditional culture and the product design}

The modern products not only are used by the domestic people, but also are sold abroad; the exchange of the products could accelerate the growth of Chinese economy. But, there are many products are similar with the others, they are usually similar in appearance, and in color; so, many designers try their best to design the innovative products, they try to integrate more new elements into their product. But, the innovation should follow some certain rules, at the sometime, the designers should ensure the functions of the products [2]. After thousands of years' development, the present remains of the Chinese traditional culture are all the quintessence; they are the heritages of the Chinese history, culture, ideology, substance, and characteristics, therefore, the designers could integrate the Chinese cultural elements into the color, patter, material, artistic conception, and shape of the products by the effective design methods; and this kind of integration is a important way to solve the cultural conflict between the Chinese culture and the overseas cultures. At some time. These designed products show the "cultural recurrence", they show the cultural quintessence of China, those products sell abroad could show the Chinese charm and Chinese characteristics to the foreigners as well.

\section{2. "Chinese style" in the product design}

The modern products often follow the need of the public; many similar products often are similar in appearance and color. Of course, some of these products are salable, but they are really lack of innovation. During the product design, "Chinese pattern" is one of the key points that the designers research and discuss. The designers could design a product by simply integrating the Chinese 
traditional elements into their design, and then a brand new product comes into being; these elements often appear in the visual aspect, such as in decoration, pattern, or appearance, they don't influence the actual using effect of the products, people could feel the Chinese style when they are using the products with Chinese traditional elements [3]. However, only the designers know very well about the Chinese traditional culture could they design the sound products with the Chinese style, and this is the essence of the localized design. It is necessary to take Chinese elements as the media, and then to understand the culture, to digest the culture, and to apply the traditional culture on producing the products. At the some time, it is necessary to create the visual difference of the products, and to integrate the Chinese aesthetics, philosophical connotation with the products so that the users could feel the strong Chinese culture style at a glance of the products, this is the real Chinese style design. The high-level design with the Chinese style not only shows the Chinese style deeply, but also shows the real quintessence of Chinese traditional culture to the users, it is the a kind of embody of the profound connotation of the Chinese traditional culture [4].

\section{The principles of applying the Chinese traditional culture to product design.}

Nowadays, a lot of products with Chinese style have been in people's daily life, no matter it is the articles for daily use, or it is the industrial products, they are all full of the feeling of Chinese characteristics. Many designers inherit and insist on the patriotism, and integrate the Chinese traditional elements with the modern products, and then they design a lot of products which are full of outstanding Chinese characteristics. But, we must notice that to design the products with Chinese elements should follow some certain principles; it can not be applied indiscriminately and abusively, or the sales volume of these products would be declined, even some products may cause a series of legal problems, such as infringement. During the process of product design, the designers should do a scientific market investigation first, know very well about the consumers' needs and what kinds of products are the very proper products that could fulfill the requests of the consumers and the manufacturers; and then, the designers should consider the actual application of the products, to design the products by analyzing the conceptions of the products; and by analyzing the consumption concepts and the aesthetic trend of the consumers[5]. What's more, if the designers want to integrate the Chinese traditional cultural elements into the products, they must study and analyzed the Chinese traditional culture overall, they must understand the essence of Chinese traditional culture, and learn the quintessence of the culture, and then design the products that are not only full of Chinese elements, but also satisfy the needs of the consumers, and the practicability and the aesthetics of the products. At the some time, the designers should not debase the products or innovate rashly in case that the products lose their original functions and values. To integrate the Chinese elements into the products, the designers could design the products in different ways, such as the color, the pattern, the textures, the material, and the implied meaning, so as to design a prefect product that could fulfill the needs of the consumers.

\section{To apply the Chinese traditional culture to the product design}

In the real life, we could easily find many products with Chinese style, the designers often apply the characteristic patterns and textures into their designs. Chinese traditional culture is broad and profound, especially, the Chinese style products usually contain lots of Chinese elements, the most distinctive representative of the elements is the Chinese theatrical mask. Nowadays, many products take the patterns of the masks as their products' identifications; we take the package of the Sichuan traditional food "Zhang Fei Beef" for example, the designer chooses the historical figure Zhang Fei for representative, and takes the mask pattern that abstracts the Character and feature of Zhang Fei by the smooth lines and the colorful elements as the identification of the beef, so that the consumers not only couldn't forget the delicious beef, but also have a deep impression of the deliberated package. In addition, the patterns of theatrical masks are also applied in the U disk, and hi-fi equipment, etc. Except the mask, the traditional patterns such as peony, orchid, plum blossom, bamboo, chrysanthemum etc, these are widely applied to the clothing, ceramic tiles, foods, 
tableware, tea sets, and so on. These patterns are complicated but magnificent and elegant, and they give the deep impressions to the people. What's more, the patterns of some mythical wild animals such as dragon, phoenix, etc, these patterns are widely applied to the designs of the construction and ornament products, for example, we could easily find these patterns are applied to the pendants, and the buildings of Chinese style, and so on. At the some time, some patterns are full of the Chinese nationality characteristics such as paper-cut, the Chinese new year paintings, they emphasize applying the textures to the products, so as to increase the culturalidentification and the sense of belonging to China.

Although the patterns and textures are very important in the product design, but the color also is a essential part of Chinese traditional culture. Because of the large territory and the different customs in different regions, the applications of the color are much different in different regions. But, these colors could give people the unforgettable impressions by its strong Chinese style. The Chinese ancients highly praise the "five-colors" — back, green, red, yellow, and white; in their opinion, they think these five colors are orthodox, they are the symbolization of honour. In the modern product design, the designers often apply the "five-elements colors"-water(blue), wood(green), fire(red), earth(yellow), metal(golden) to the products, and the "four seasons colors" —winter (white, silver), spring (pink, purple, red), summer(green, black, orange), autumn(yellow, gray, golden) as well[6]. The most representative colors are red and golden, and these two colors are the main representatives of the Chinese style colors. For example, during the traditional Chinese spring festival, the antithetical couplet, FOOK, lantern, paper-cut, firecrackers are mainly in red or in golden. In addition, the relevant clothing and ornaments in a wedding are almost in red, this color represent the ebullient character of Chinese people. Except the red and golden products, we also could easily find the porcelains that are in green, blue, and black. What's more, to apply the Chinese ink painting which are full of Chinese style to the fans is also the wonderful way of the product design.

In the modern product design, to apply the proper materials is an effective way to show Chinese traditional culture. Although there are various materials for product design, but as the constant development of Chinese history and culture, there are some special materials which are only applied in China; so the foreign consumers could easily distinguish the products that have applied these special materials come from China. The first handicraft technology monograph of China-Kao Gong Ji, which also is translated the Artificers' Record-records that there are lots of factors that determine a perfect design, such as time, weather, geographical position, material, technique, and so on; only the designers follow all these objective laws and coordinate the relationship of these laws well could they design a perfect product. Therefore, from the ancient to today, Chinese designers had been paid attention to choosing the proper materials. During the constant development of China, the designers had had a sound understanding on choosing and applying the proper materials. Mastering the specialty and the quality of the materials well is a very important ability of a good designer. During the many years' development, the designers often apply the the pottery and porcelain, silk, cotton, red stoneware, jade, bamboo and rattan in their designs, these materials not only are full of Chinese style, but also brings the comfortable feeling of texture to the consumers, at the some time, they could also bring the artistic conception of the Chinese style to the consumers. For example, the silk fan, which are made up of silk, jade, and scented wood, is one of the representative products with Chinese style. In general, the fan spikes are usually in red or in golden, and the patterns on the sector usually are peony, plum blossom, orchid, and the historical figures, so that the consumers could easily feel the charm of Chinese style. Therefore, to apply the proper Chinese traditional materials in the products could not only let the consumers enjoy this kind of Chinese style, but also promote the traditional materials to be revived.

\section{References}

[1] Bai Xuetao. Discussion on the Application of the Chinese Traditional Culture to the Modern Industrial Product[J]. Chemical Enterprise Management, 2016,15:16. 
[2] Zhang Ming. From "Chinese Pattern" to "Chinese Mode"-Research on the Method of Designing the Localized Product in Global Perspective[J]. Journal of Nanjing Arts Institute (Fine Arts \& Design), 2016,04:197-201.

[3] Zhou Yaqi, Zong Mingming. Research on the Application of the Chinese Traditional Arts to the Design of the Modern Product----Take Paper-cut for Example[J]. Design, 2014,11:13-14.

[4] Zhang Moli. Research on the Application of the Taoism to the Modern Product Design-Take Tea Set for Example[J]. Art Panorama, 2015,08:110.

[5] Hu Ping, Wang Chenxuan, Meng Shuangshuang. The Inherit of the culture-Research on the application of the Five-morality Theory of the Confucianism to the Modern Product Design[D]. China Packaging Industry, 2013,18:68-69.

[6] Chen Jianxin, Zhang Xinyue. The Integration of the Nationality and the Modernity----Brief Discuss the Application of the Chinese elements in the Product Design[J]. Art Science and Technology, 2014,05:420+411+414. 